\title{
STUDY OF GLYCAEMIC BIOMARKERS IN THE PATIENTS OF THYROID DISORDERS
}

\author{
Varsha Chowdhry', G. G. Kaushik ${ }^{2}$
}

${ }^{1}$ Senior Demonstrator, JLN Medical College, Ajmer.

${ }^{2}$ Senior Professor and HOD, Department of Biochemistry, JLN Medical College, Ajmer.

ABSTRACT
BACKGROUND
Thyroid disorders are commonest disorders worldwide. Various glycated proteins can be used as glycaemic biomarkers to
determine the degree of glycaemia in thyroid patients. They are useful glycaemic biomarkers to monitor the short-term glycaemic
changes in the patients with thyroid disorders and have a role in conjugation with glycated haemoglobin. Serum fructosamine and
glycated albumin correlate well with serum glucose.
So, the present study was conducted to evaluate the changes and compare the levels of various glycaemic biomarkers like
serum fructosamine, glycated albumin, glycated haemoglobin in overt hypothyroid, subclinical hypothyroid, hyperthyroid patients
in comparison to controls and the levels of total protein and serum albumin was estimated in thyroid disorder patients.

\section{MATERIALS AND METHODS}

The present descriptive comparative study has been conducted on 300 subjects of either sex of various age groups. Study included diagnosed thyroid disorder patients (200) attending medical OPD, patients admitted in medical and surgical wards and patients coming in Radioimmunoassay (RIA) laboratory, Biochemistry Department, JLN Medical College and Hospital, Ajmer. The results of patients were compared with the hundred healthy subjects of either sex of similar age group. The indices included: - Serum fructosamine assayed by Nitroblue Tetrazolium Kinetic Method, Serum Glycated Albumin by Enzyme-Linked Immunosorbent Assay, Total protein by Biuret method, Fasting blood glucose by GOD-POD method and HbA1c by Ion-Exchange Resin Method.

\section{RESULTS}

The mean serum fructosamine were higher in overt hypothyroid and subclinical hypothyroid patients in comparison to healthy control, vice-a-versa was found in hyperthyroid patients ( $p<0.001)(H S)$. Mean glycated albumin levels were higher in overt hypothyroid patients $(\mathrm{p}<0.005)$ and subclinical hypothyroid patients in comparison to healthy control, vice-a-versa was found in hyperthyroid patients. Total protein levels were higher in overt hypothyroid and subclinical hypothyroid patients. Serum albumin levels were higher in overt hypothyroid patients in comparison to hyperthyroid and healthy control, which was statistically significant.

\section{CONCLUSION}

The present study concluded that serum fructosamine and serum glycated albumin are better short-term glycaemic markers than glycated haemoglobin and fasting blood glucose level in thyroid disorder patients.

\section{KEYWORDS}

Serum Fructosamine, Glycated Albumin, Glycated Haemoglobin.

HOW TO CITE THIS ARTICLE: Chowdhry V, Kaushik GG. Study of glycaemic biomarkers in the patients of thyroid disorders. J. Evolution Med. Dent. Sci. 2017;6(72):5159-5163, DOI: 10.14260/Jemds/2017/1120

\section{BACKGROUND}

Thyroid diseases are medical conditions impairing the functions of the thyroid gland. Imbalance in production of thyroid hormone arises from dysfunction of the thyroid gland itself or pituitary gland, which produces the thyroid stimulating hormone (TSH) which is regulated by thyrotropin-releasing hormone produced by the hypothalamus. The concentration of TSH increases with age, requiring age related correction (MI Surks et al, 2007).(1)

Hypothyroidism and hyperthyroidism are the two principal pathological conditions that involves the thyroid gland. Other thyroid disorders include subclinical

Financial or Other, Competing Interest: None.

Submission 27-07-2017, Peer Review 24-08-2017,

Acceptance 30-08-2017, Published 07-09-2017.

Corresponding Author:

Dr. Varsha Chowdhry,

Senior Demonstrator,

JLN Medical College,

Ajmer.

E-mail: varshachowdhry@gmail.com

DOI: $10.14260 /$ jemds $/ 2017 / 1120$

\section{(c) $(\mathbf{F})$}

hypothyroidism and overt hypothyroidism), etc. (Komorica $\mathrm{E}$ et al, 2012).(2) Hypothyroidism is defined as deficiency of thyroid hormone secretion and action. Common causes are autoimmune disorders like Hashimoto thyroiditis, iodine deficiency, removal of thyroid gland, etc. Subclinical hypothyroidism is defined as asymptomatic state, characterised by normal concentration of $\mathrm{T}_{4}$ and $\mathrm{T}_{3}$ and elevated level of thyroid stimulating hormone.

Overt hypothyroidism is defined as clinical syndrome of hypothyroidism associated with elevated TSH level (thyroid stimulating hormone) and decreased serum levels of T3 and T4.

Hyperthyroidism is defined as a hypermetabolic state caused by excessive production of thyroid hormones. Some clinicians prefer the term "thyrotoxicosis." Common causes are Grave's disease, Hashimoto thyroiditis, toxic nodule, etc.

Various glycated proteins like serum fructosamine, glycated albumin and glycated haemoglobin can be used as glycaemic biomarkers to determine the degree of glycaemia in the individual's prediabetic conditions (like thyroid diseases). The use of long-term measures (2 - 3 months) of glycation like glycated haemoglobin (HbA1c) is the 
cornerstone of assessing glycaemic control. Other glycated plasma proteins include serum fructosamine and glycated albumin (GA), which are also formed non-enzymatically (Armbruster DA et al, 1987).(3) Fructosamine is a measure of average glycaemia over a shorter period ( 2 - 3 weeks) than HbA1c, but its concentration in plasma is much more stable than that of glucose itself and is much easier to measure than true mean blood glucose (MBG).

Lack of linear correlation between HbA1c levels and average glucose concentration arises because of numerous factors affecting $\mathrm{HbA1c}$ including thyroid diseases, haematological factors, etc. Owing to this, other glycated proteins are also used as glycaemic biomarkers.

The advantage of glycated proteins, serum fructosamine and glycated albumin is that their glycation is unaffected by RBC lifespan. Therefore, factors such as RBC permeability to glucose would not be expected to affect their glycation (Wright et al, 2012). ${ }^{(4,5)}$

Serum fructosamine is an useful indicator of peripheral metabolic functions in patients with thyroid diseases (H. Hara et al, 1990).(6)

Glycated albumin is an alternative glycaemic marker, which is more accurate for the assessment of glycaemic control than HbA1c (M. Inaba et al, 2007).(6) However, glycated albumin values are influenced by several physiological factors or diseases associated with albumin turnover (T. Okada et al, 2009).(7)

Glycated albumin (GA) ${ }^{(8)}$ more accurately reflects changes in plasma glucose during the short term and postprandial plasma glucose. It reflects mean glucose over the period of 2 3 weeks (N. Furusyo et al, 2013). Glycated albumin reacts with glucose ten times more rapidly than $\mathrm{HbA1c}$ and has shorter life, which makes it more reliable for indicating glycaemic states (A. Arasteh et al, 2014).(9)

All currently available glycaemic biomarkers have advantages and limitations, which was shown earlier by various studies. So, the present study has been conducted to evaluate the importance of various glycaemic biomarkers in the patients with thyroid diseases.

\section{MATERIALS AND METHODS}

The present descriptive comparative study was conducted on 300 subjects, of either sex of various age groups. Study included diagnosed thyroid disorder patients attending Medical OPD, patients admitted in medical and surgical wards and patients coming in Radioimmunoassay (RIA) laboratory, Biochemistry Department, JLN Medical College and Hospital, Ajmer. The results of patients were compared with the hundred healthy subjects of either sex of similar age group.

\section{The Selected Subjects were Further Grouped as-}

1. Group I: Healthy control (Euthyroid subjects) $(n=100)$. It was ensured by routine examination that all the subjects were healthy and there were no signs and symptoms or positive thyroid history.

2. Group II: It included the clinically established patients of overt hypothyroidism $(n=70)$.

3. Group III: It included clinically established patients of subclinical hypothyroidism $(\mathrm{n}=60)$.

4. Group IV: It included clinically established patients of hyperthyroidism $(n=70)$.

\section{Exclusion Criteria}

Patients taking lipid lowering drugs, diabetic patients, patients with chronic liver diseases, patients on steroid therapy, patients having clinical evidence of acute illness or malignancy.

\section{Study Design}

Prospective, case control study.

Outcome Analysis (Statistical Analysis)

Interpretation was done according to $\mathrm{p}$-value.

$\mathrm{P}<0.005$ significant.

$\mathrm{P}<0.001$ highly significant.

\section{Collection and Analysis of Blood Sample}

Written consent was obtained from all the subjects participating in the study.

Blood samples were collected by venepuncture, using aseptic technique. The serum was separated by centrifugation and was analysed for the following biochemical parameter.

\section{Samples were Analysed for}

1. Serum fructosamine- By NBT (Nitroblue tetrazolium) method (J. Barker et al, 1983).(10)

2. Serum Total Protein- By Biuret method (Koller A, et al, 1984).(11)

3. Serum Albumin- Bromocresol Green Method (Rodkey FL, et al, 1984).(12,13)

4. Fasting Blood Glucose- By enzymatic GOD-POD, End point method (P Trinder, 1969).(14)

5. Glycated Haemoglobin $\left(\mathrm{HbA}_{1 \mathrm{c}}\right)$ - By Ion-Exchange Resin method (P Trivelli et al, 1971).

6. Glycated albumin- By Enzyme-linked Immunosorbent Assay.

7. Haemoglobin- By Drabkin and Austin JH, 1932.(15)

Procedure of Serum Fructosamine (Colorimetric Method) Take three test tubes, mark them as blank, standard and test. Add 100 microlitres of working reagent in all the three test tubes. Add 100 microlitres of calibrator in standard test tube and 100 microlitres of sample in test. Mix and incubate at 37 degrees for 10 mins. Take the reading at wavelength $520 \mathrm{~nm}$ (green filter).

\section{Calculations}

\section{$\mathrm{A}=$ ABSORBANCE}

Serum Fructosamine $(\mu \mathrm{mol} / \mathrm{L}=$ absorbance of sample/absorbance of standard

$\times$ concentration of standard

Normal range of serum fructosamine in non-diabetic patients is $187-287 \mu \mathrm{mol} / \mathrm{L}$

\section{Estimation of Serum Glycated Albumin}

Glycated albumin was analysed by ELISA-KIT, the quantitative sandwich enzyme immune assay technique. The microtitre plate provided in this kit was precoated with monoclonal antibodies specific for glycated albumin, standard or sample (50 $\mu$ litre) was added; $100 \mu$ litre of conjugate to each well was added mixed and incubated for one hour followed by washing the microtitre plate, then 50 $\mu$ litre substrate A to each well was added, $50 \mu$ litre of substrate B followed by $50 \mu$ litre of stop solution. Optical density was calculated at $450 \mathrm{~nm}$. 
Standard curve was plotted and the value was obtained. Normal range was $11 \%-16 \%$.

\section{Estimation of Total Protein- Biuret, Colorimetric Method}

Protein give an intense violet blue colour complex with copper salts in an alkaline medium. Reagents were ready to use-

Reagents in kit

$\mathrm{R}$ (biuret)

Total protein calibrator

$1000 \mu$ litre $\mathrm{R}$ reagent was taken in three test tubes blank, standard, sample $1000 \mu$ litre of R was added in all three test tubes followed by $25 \mu$ litre of standard in S test tube and 25 $\mu$ litre of sample in sample test tube. Optical density was taken at $540 \mathrm{~nm}$.

Normal range $6.6-8.3 \mathrm{gm} / \mathrm{dL}$.

Estimation of serum albumin.

Bromocresol green colorimetric method (end point).

Three test tubes were taken and $1000 \mu$ litre of $\mathrm{R}$ reagent was added, then $5 \mu$ litre standard was added in standard test tube and samples were added and test optical density was calculated at the wavelength of $630 \mathrm{~nm}$. Intensity of colour is directly proportionate to the concentration of sample.

\section{Estimation of Fasting Blood Glucose}

The aldehyde group of glucose is oxidised by glucose oxidase to give gluconic acid and hydrogen peroxide. Hydrogen peroxide is broken down to water and nascent oxygen by hydrogen peroxidase enzyme the oxygen reacts with 4aminoantipyrine in the presence of phenol to form pink colour complex absorbance of quinoneimine complex so formed is directly proportionate to glucose concentration.

\section{RESULTS}

Present descriptive comparative study showed that among the 100 euthyroid subjects 40 subjects were males, while 60 subjects were females. Overt hypothyroid patients included 20 males and 50 females. Subclinical hypothyroid patients included 26 males and 34 females, while 20 males and 50 females were included in the hyperthyroid patients. So females were more affected by thyroid disorders (64\%) than males (35\%) (Table 1). Similar results were also shown in the study conducted by Bojoro $\mathrm{T}$ et al (2000), where $2.5 \%$ of females and $0.6 \%$ of males reported to have hyperthyroidism (sex ratio female: male, 4:2). The prevalence of hypothyroidism was $0.9 \%$ and $4.8 \%$ for males and females respectively in the Norway city. In the study, it was concluded that difference in autoimmunity in males and females is an important factor for the above prevalence. The mean serum fructosamine levels were higher in overt hypothyroid (581.65 \pm 51.11) and subclinical hypothyroid (372.93 \pm 43.94) patients in comparison to euthyroid subjects (260.70 \pm 20.06) and vice-a-versa was found in the hyperthyroid patients which was highly significant (Table 2/Fig. 2). Serum fructosamine levels were highly significant $(\mathrm{P}<0.001)$ and correlated among the different groups of thyroid disorders.

Mean glycated albumin levels were higher in overt hypothyroid patients and subclinical hypothyroid patients $18.0 \pm 2.0$ in comparison to euthyroid subjects and vice-aversa was found in hyperthyroid patients where it was significantly low $11 \pm 2.0$ in comparison to euthyroid patients $14 \pm 1.4$ as shown in Table 2 .

The postulation put forward for the abnormally high fructosamine and glycated albumin levels in absence of clinical hypoglycaemia in hypothyroid patients are-

Deterioration of protein metabolism which further decreases turnover of proteins and increase of half-life of protein, increase in glycation of protein via auto oxidative glycation in case of oxidative stress increase in protein carbonylation, serum malondialdehyde and decreased glutathione level in hypothyroid cases explains increased peroxidation of lipids. This might be a contributing factor for increased radical mediated protein glycation, low-grade inflammation and free radical formation causes manifold increase in immunoglobulin production. This explains glycation of these immunoglobulins.(13) Disturbance in glucose homeostasis with decreased glucose absorption and utilisation leads to insulin resistance. This further causes glycation of protein. The tendency of glycated proteins to accumulate in tissues, resisting easy proteolysis are further source of free radicals.

Above findings were similar to the data reported by Kondaveti S, et al (2014).(16)

Thyroid hormone promotes albumin metabolism. Hyperthyroidism is a hypermetabolic state and there is increased turnover of proteins, but in hypothyroidism albumin metabolism is prolonged. Glycated albumin levels decrease in the patients with nephrotic syndrome, which shortens the half-life of serum albumin and increases in the patients with liver cirrhosis which prolongs the half-life of serum albumin.(16)

In present study, it was found that mean $\mathrm{HbA}_{1 \mathrm{c}}$ level was slightly raised in overt hypothyroid and subclinical hypothyroid patients in comparison to euthyroid subject and vice-a-versa was found in hyperthyroid patients, but the levels were within the normal range as diabetic patients were excluded. Mean fasting glucose levels were found to be slightly higher in thyroid disorder compared to euthyroid subjects, but difference was not found to be statistically significant (Table 2).

In the present descriptive comparative study, total protein was $7.5 \pm 0.93$ and $7.3 \pm 0.61(\mathrm{gm} / \mathrm{dL})$ in overt hypothyroid patients and subclinical hypothyroid patients respectively which is higher than euthyroid subjects (6.1 \pm 0.4 ), whereas it was $4.86 \pm 0.42$ in hyperthyroid patients but the results were found to be within the normal range (Table 3).

\section{The Probable Cause of above Results could be(16)}

1). Deterioration of protein metabolism, 2). Decrease turnover of protein, 3). Increase half-life of protein in hypothyroid patients, 4). Increase in the glycation of protein via auto-oxidative glycation, 5). Increase in oxidative stress, 6). Decreased glutathione levels that increases free radicals, 7). Disturbance in glucose homeostasis with decreased glucose absorption and utilisation leads to insulin resistance, which further causes glycation of protein.

Level of serum albumin was less in hyperthyroid patients $(3.1 \pm 0.38)$ in comparison to euthyroid subjects $(3.5 \pm 0.30)$; overt hypothyroid patients $(3.8 \pm 0.43)$ and subclinical hypothyroid patients $(4.2 \pm 0.43)$ (Table 4$)$. 
Statistically significant correlation was found ( $\mathrm{p}<0.005)$ when intergroup comparison was done among overt hypothyroid, subclinical hypothyroid patients and hyperthyroid patients (Table $5(\mathrm{~A}, \mathrm{~B}, \mathrm{C})$ ). Our study is in accordance with Kondaveeti $S$ et al, (2014)(16) and Lee MH et al (1992).(15)

The decreased serum albumin level in hyperthyroid patients in comparison to hypothyroid patients in nonclinical hyperglycaemia patients is because of decreased turnover of protein, increased half-life of proteins and increased glycation of protein via auto-oxidative stress.(16)

So the study concludes that serum fructosamine and glycated albumin are better short-term glycaemic biomarkers than HbA1C and fasting plasma glucose levels in thyroid disorder patients. Total protein and serum albumin levels were also found to be higher in overt hypothyroid and subclinical hypothyroid patients.

\section{Observations}

\begin{tabular}{|c|c|c|}
\hline Sl. No. & Study Group & No. of Subjects (n) \\
\hline Group I & Euthyroid & 100 \\
\hline Group II & Overt hypothyroid & 70 \\
\hline Group III & Subclinical hypothyroid & 60 \\
\hline Group IV & Hyperthyroid & 70 \\
\hline & Total & 300 \\
\hline
\end{tabular}

${ }^{*} \mathrm{n}=$ Number of subjects

\begin{tabular}{|c|c|c|c|c|}
\hline \multirow{2}{*}{ Sl. No. } & \multirow{2}{*}{ Group Studied } & \multicolumn{3}{|c|}{ No. of Subjects } \\
\cline { 3 - 5 } & Euthyroid & 40 & 60 & 100 \\
\hline 1 & Overt hypothyroid & 20 & 50 & 70 \\
\hline 2 & Subclinical hypothyroid & 26 & 34 & 60 \\
\hline 3 & Hyperthyroid & 20 & 50 & 70 \\
\hline 4 & Total & $\mathbf{1 0 6}$ & $\mathbf{1 9 4}$ & $\mathbf{3 0 0}$ \\
\hline \multicolumn{4}{|c|}{ Table 1a. Distribution of Subjects Studied in } \\
Relation to Sex
\end{tabular}

Females are more affected than males. The possible reason for females getting more affected could be difference in immune response, organ vulnerability, reproductive function, sex hormones susceptibility and severity of autoimmune disease. Females show increased immune reactivity, difference in number or responsiveness of cell that constitute the immune response.

\begin{tabular}{|c|c|c|c|c|}
\hline Tests & Euthyroid & Overt Hypothyroid & Subclinical Hypothyroid & Hyperthyroid \\
\hline FPG $(\mathrm{mg} / \mathrm{dL})$ & $84.24 \pm 11.23$ & $90.65 \pm 13.51$ & $87.80 \pm 13.14$ & $92.31 \pm 12.2$ \\
\hline $\mathrm{HbA}_{1 \mathrm{C}}(\%)$ & $5.03 \pm 0.53$ & $6.0 \pm 0.58$ & $5.31 \pm 0.56$ & $5.15 \pm 0.45$ \\
\hline Fructosamine $(\mu \mathrm{mol} / \mathrm{L})$ & $260.70 \pm 26.06$ & $581.65 \pm 51.11$ & $372 \pm 43.94$ & $162 \pm 23.46$ \\
\hline Glycated $(\%)$ Albumin & $14.1 \pm 1.4$ & $20 \pm 2.5$ & $18 \pm 2.0$ & $11 \pm 2.0$ \\
\hline \multicolumn{5}{|r}{ Table 2. Glycaemic Profile in Subject Studied } \\
\hline
\end{tabular}

Serum fructosamine levels were low in the hyperthyroid patients against the control group (162 $\pm 23.46 \mathrm{v} / \mathrm{s} 260.70 \pm 26.06)$ (p $<0.001$ ) (HS), whereas the fasting plasma glucose levels were higher $92.31 \pm 12.2$ in comparison to euthyroid subjects. Significant positive correlation was found between the FPG and fructosamine level ( $r=0.977, p<0.001)$. Glycated albumin levels were significantly high in the overt hypothyroid patients $(20 \pm 2.5)$ and subclinical hypothyroid patients in comparison to euthyroid subjects $(14 \pm 1.4)$ ( $p$ value was $<0.001)$.

\begin{tabular}{|c|c|c|c|c|}
\hline Test & Euthyroid & Overt Hypothyroid & $\begin{array}{c}\text { Subclinical } \\
\text { Hypothyroidism }\end{array}$ & Hyperthyroidism \\
\hline Total protein (g/dL) & $6.1 \pm 0.4$ & $7.5 \pm 0.93$ & $7.3 \pm 0.61$ & $4.86 \pm 0.42$ \\
\hline \multicolumn{2}{|c|}{ Table 3. Comparison of Total Protein between Euthyroid and Overt Hypothyroid Subclinical Hypothyroidism and } \\
Hyperthyroidism
\end{tabular}

* NS (non-significant) as compared to euthyroid subjects.

\begin{tabular}{|c|c|c|c|c|}
\hline Test & Euthyroid & Overt Hypothyroidism & $\begin{array}{c}\text { Subclinical } \\
\text { Hypothyroidism }\end{array}$ & Hyperthyroidism \\
\hline Serum albumin & $3.5 \pm 0.3$ & $3.8 \pm 0.43$ & $4.2 \pm 0.43$ & $3.1 \pm 0.38$ \\
\hline Table 4. Comparison of Serum Albumin Value between Euthyroid, Overt Hypothyroidism, Subclinical Hypothyroidism and \\
Hyperthyroid Subjects
\end{tabular}

\begin{tabular}{|c|c|c|c|}
\hline Test & Euthyroid Subjects & Hyperthyroid Patients & P-value \\
\hline Serum albumin & $3.5 \pm 0.30$ & $3.1 \pm 0.38$ & $<0.05$ \\
\hline \multicolumn{2}{|c|}{ Table 5A. Comparison of Serum Albumin Levels between Euthyroid Subjects and Hyperthyroid Patients } \\
\hline
\end{tabular}

\begin{tabular}{|c|c|c|c|}
\hline Test & Overt Hypothyroid & Hyperthyroid & P-value \\
\hline Serum albumin & $3.8 \pm 0.43$ & $3.4 \pm 0.38$ & $\mathrm{p}<0.05(\mathrm{~S})$ \\
\hline \multicolumn{4}{|c|}{ B. Comparison of Serum Albumin Level in Overt Hypothyroid and Hyperthyroid Patients } \\
\hline
\end{tabular}




\begin{tabular}{|c|c|c|c|}
\hline Test & Subclinical Hypothyroid Patients & Hyperthyroid Patients & P-value \\
\hline Serum albumin & $4.2 \pm 0.43$ & $3.10 \pm 0.43$ & $<0.05(\mathrm{~S})$ \\
\hline C. Comparison of Serum Albumin Levels between Subclinical Hypothyroid Patients and Hyperthyroid Patients \\
\hline
\end{tabular}

* S = significant

\section{DISCUSSION}

For the patients suffering from thyroid disease a comparative study of various biochemical parameters like serum fructosamine, glycated albumin, glycated haemoglobin, FBG, total protein and serum albumin was carried out. Keeping in mind that thyroid hormone affects protein and carbohydrate metabolism, so in hyperthyroidism there is increase in protein turnover as hyperthyroidism is a hypermetabolic state, but in hypothyroidism albumin metabolism is prolonged. Serum fructosamine, glycated albumin, total protein and serum albumin levels were increased in hypothyroidism and decreased in hyperthyroidism. FBG were high in hyperthyroidism and low in hypothyroidism. These findings were in agreement with the previously reported data on carbohydrate metabolism. A significant positive association was found between FBG level and FA level ( $p<$ 0.001), which was highly significant.

R Rangaswamy et al (2013)(17) concluded that serum fructosamine values were found to be significantly correlated among the different groups of thyroid disorders $(\mathrm{P}=0.001)$. In thyroid disorder the sensitivity, specificity, PPV and NPV in hypothyroidism is $100 \%, 96.4 \%, 100 \%$ and $100 \%$ and hyperthyroidism is $75 \%, 92.9 \%, 42.6 \%$ and $100 \%$ respectively. Albumin values negatively correlated with hypothyroidism, which was statistically significant. Significant correlation was found between $\mathrm{T}_{3}, \mathrm{~T}_{4}, \mathrm{TSH}$ and fructosamine levels. It was concluded that it is useful to consider serum fructosamine as diagnostic indicator in patients with thyroid disease.

\section{CONCLUSION}

So it is concluded in the present study that FA, serum glycated albumin are better short-term glycaemic biomarkers than HbA1c and fasting plasma glucose levels in thyroid disorder patients, total protein and serum albumin levels were also found to be higher in overt hypothyroid and subclinical hypothyroid patients and vice-a-versa was found in hyperthyroid patients in comparison to euthyroid subjects.

\section{REFERENCES}

[1] Surks MI, Hollowell JG. Age specific distribution of severe thyrotropin and antithyroid antibodies in the US population: implication for the prevalence of subclinical hypothyroidism. J Clin Endocrinol Metab 2007;92(12):4575-82.

[2] Billic-Komarica E, Beciragic A, Junuzovic D. The importance of $\mathrm{HbA1}_{\mathrm{C}}$ control in patients with subclinical hypothyroidism. Mater Socio Medica 2012;24(2):212-9.

[3] Armbruster DA. Fructosamine: structure, analysis, and clinical usefulness. Clin Chem 1987;33(12):2153-63.
[4] Weijers RN, Slaats EH, Kruijswijk H. Fructosamine value in hyperthyroidism, hypothyroidism and gammopathy. Weinklin Wonchenschr 1990;180:21-4.

[5] Alarcon-Casas LW, Hirsch IB. The challenge of the use of glycemic biomarkers in diabetes: refection on haemoglobin A1c, 1, 5-androhydroglycitol, and the glycated proteins, fructosamine and glycated albumin. Diabetic spectrum 2012;25(3):141-8.

[6] Hara H, Ban Y, Taniyama M, et al. The significance of serum fructosamine measurement in patients with thyroid diseases. Nihon Naibunpi Gakkai Zasshi 1990;66(10):1075-84.

[7] Okada T, Nakao T, Matsumoto H, et al. Influence of age nutritional status on glycated albumin values in hemodialysis patients. Inter Med 2009;48:1495-9.

[8] Inaba M, Okuiso S, Kuneda Y, et al. Glycated albumin is a better glycemic indicator than glycated haemoglobin values in haemodialysis patients with diabetes: effect of anaemia and erythropoietin injection. J Am Soc Nephrol 2007;18(3):886-903.

[9] Arasteh A, Farahi S, Habib-Rezaei M, et al. Glycated albumin: an overview of the in vitro models of an in vivo potential disease marker. Journal of diabetes and metabolic disorders 2014;13:49.

[10] Baker JR, O'Connor JP, Metcalf PA, et al. Clinical usefulness of estimation of serum fructosamine concentration as a screening test for diabetes mellitus. Br Med J 1983;287(6396):863-7.

[11] Koller A, Kaplan A. The C.V. Mosby Co St. Louis toronto princeton. Clin Chem 1984;418:1316-24.

[12] Trinder P. Determination of blood glucose using an oxidase-peroxidase system with a non-carcinogenic chromogen. J Clin Pathol 1969;22(2):158-61.

[13] Otosu T, Nishimoto E, Yamashita S. Multiple conformational state of human serum albumin around single tryptophan residue at various $\mathrm{pH}$ revealed by time resolved fluorescence spectroscopy. J Biochem 2010;147(2):191-200.

[14] Bjoro T, Holmen J, Okroger K, et al. Prevalence of thyroid disease, thyroid dysfunction and thyroid peroxidase antibodies is a large, unselected population. European Journal of Endocrinology 2000;143:639-47.

[15] Kim MK, Kwon HS, Baek KH, et al. Effects of thyroid hormone on $\mathrm{A} 1 \mathrm{C}$ and glycated albumin levels in nondiabetic subjects will overt hypothyroidism. Diabetes care 2010;33(12):2546-8.

[16] Kondaveeti SB, Shaker IA. Estimation of glycated albumin in various thyroid disorders. Int J Cur Res 2014;6(9):138-44.

[17] Rangaswamy R, Sreekaitha, D'souza V. Fructosamine assay as a diagnostic criterion in thyroid disorders. International Journal of Medical and Health sciences 2013;2(2):170-5. 